\title{
EVALUASI PENGARUH FUNGSI PEMETAAN TERHADAP KINERJA DAN KONSUMSI DAYA CACHE MEMORY
}

\author{
Tati Erlina ${ }^{1)}$, Rahmi Eka Putri ${ }^{2)}$ \\ Jurusan Sistem Komputer Fakultas Teknologi Informasi \\ Universitas Andalas \\ Kampus Limau Manis Unand, PADANG \\ tatierlina@fti.unand.ac.id ${ }^{\mathbf{1})}$, rahmi230784@gmail.com ${ }^{2}$
}

\begin{abstract}
Abstrak
Menciptakan komputer yang berkinerja tinggi dan mengkonsumsi daya minimal merupakan salah satu fokus yang menjadi tren penelitian dalam bidang arsitektur komputer belakangan ini. Diketahui bahwa sejumlah faktor berpengaruh dalam menentukan kinerja dan konsumsi daya dari setiap elemen pembangun komputer dan pada akhirnya mempengaruhi kinerja dan konsumsi daya sebuah komputer secara keseluruhan. Fokus penelitian ini adalah untuk mengetahui seberapa besar pengaruh dari fungsi pemetaan (mapping techniques) sebagai salah satu jenis elemen perancangan yang diterapkan pada sebuah cache memory terhadap kinerja dan konsumsi daya dari cache memory dengan mensimulasikannya pada SMPCache dengan berbagai macam benchmark dan CACTI.
\end{abstract}

Kata kunci:

Cache memory, Konsumsi Daya, Kinerja, SMPCache, CACTI, Cache Miss, Cache Hit

\begin{abstract}
Creating high performance computers which consume minimal power is one of the focus and has become the trend of research in the field of computer architecture lately. It has been known that a number of factors influence the determination of the performance and power consumption of each of the building elements of the computer and ultimately affect the performance and overall power consumption of a computer. The focus of this research is to find out how much mapping functions as one of the type of design elements applied to a cache memory influence the performance and power consumption of the cache memory by simulating various configuration elements
\end{abstract}

of the design in SMPCache with various benchmarks and CACTI.

Keywords:

Cache memory, Power Consumption, Performance, SMPCache, CACTI, Cache Miss, Cache Hit

\section{Pendahuluan}

Sejak beberapa puluh tahun yang lalu, kinerja microprocessor berkembang dengan sangat pesat. Hal ini dicapai diantaranya dengan tingginya clock frequency operasi microprocessor dan adanya pengintegrasian beberapa inti processor ke dalam satu chip. Akan tetapi, komponen utama pembangun komputer lainnya seperti main memory tidak mampu mengimbangi perkembangan kecepatan microprocessor tersebut, sehingga terdapat perbedaan yang sangat signifikan antara kecepatan main memory dan microprocessor. Hal ini menyebabkan adanya "bottleneck" pada kinerja processor. Salah satu langkah yang sudah dilakukan untuk menyelesaikan masalah tersebut adalah dengan menggunakan cache memory.

Cache memory, disebut juga sebagai Central Processing Unit (CPU) memory adalah sebuah memory yang dapat diakses oleh microprocessor dengan lebih cepat dibanding main memory. Salah satu penyebabnya adalah cache memory diposisikan sedemikian rupa pada chip yang sama dengan microprocessor, sehingga waktu yang dibutuhkan microprocessor untuk mengakses cache memory menurun secara signifikan. Setiap saat, cache memory menyimpan salinan sebagian data yang tersimpan di main memory sehingga ketika processor perlu mengakses data dari main memory, maka processor dapat mengakses salinan data yang dibutuhkannya 
tersebut dari cache memory. Dengan demikian, keberadaan cache memory dapat mengurangi ketimpangan kecepatan antara main memory dan microprocessor dan secara langsung berkontribusi penting dalam meningkatkan kecepatan komputer secara keseluruhan.

Bersamaan dengan keuntungan penggunaan cache memory dalam perancangan microprocessor moderen, cache memory juga memiliki kekurangan yang perlu ditangani, dimana cache memory merupakan salah satu komponen yang paling banyak mengkonsumsi daya dalam arsitektur Komputer (Saito et al., 2016). Salah satu penyebabnya adalah karena cache biasanya merupakan struktur terbesar pembangun sebuah microprocessor, sehingga cache memory menjadi sumber utama disipasi daya statis. Hal ini tentu saja tidak sejalan dengan fokus kalangan industri untuk menciptakan microprocessor yang memiliki kinerja tinggi dan mengkonsumsi daya yang lebih sedikit (Kothari, 2011). Menekan konsumsi daya ini menjadi sangat penting karena beberapa alasan (Zhu, 2011), diantaranya yaitu konsumsi daya sangat berpengaruh pada pembatasan kerapatan elemen pembangun processor, kebutuhan pendinginan sistem, keandalan sistem serta masa hidup baterai terutama pada portable system.

Diketahui bahwa, terdapat banyak faktor yang mempengaruhi besarnya konsumsi daya dari sebuah cache memory. Salah satu hal yang berpengaruh besar yaitu pemilihan strategi yang diterapkan pada saat perancangan cache memory (Abella and Gonzales, 2003). Elemen-elemen strategi perancangan yang dimaksud adalah seperti jenis mapping techniques yang digunakan serta ukuran memory cache. Dimana faktor-faktor tersebut tidak hanya berpengaruh terhadap kinerja sebuah cache memory, akan tetapi juga berpengaruh terhadap konsumsi daya sebuah microprocessor secara keseluruhan. Oleh karena itu, pada penelitian ini, penulis mengekplorasi beberapa aspek perancangan cache memory dan bagaimana pengaruhnya terhadap kinerja serta konsumsi daya dari sebuah cache memory.

Dalam penelitian ini sebuah simulasi dilakukan terhadap beragam konfigurasi menggunakan SMPCache (Symmetric Multiprocessors Cache Simulator) dan CACTI untuk mengetahui seberapa besar pengaruh teknik pemetaan sebagai salah satu jenis elemen perancangan yang cache yang diterapkan dapat mempengaruhi kinerja cache memory yang terutama diukur dari cache hit yang dihasilkan dan besarnya konsumsi daya yang digunakan.

\section{KAJIAN LITERATUR}

\section{II.1 Prinsip-prinsip Cache memory}

Perangkat keras pembangun sistem komputer modern terdiri atas sejumlah komponen pembangun yang harus bekerja sama lain. Setiap komponen yang terlibat berkontribusi dalam menentukan kinerja komputer secara keseluruhan. Agar kinerja yang diharapkan dapat tercapai, maka setiap komponen harus dapat mengimbangi kinerja komponen lainnya. Akan tetapi, pada prakteknya, terjadi ketimpangan kecepatan yang cukup signifikan antara processor dengan main memory. Oleh karena itu, sejumlah strategi sudah dilakukan, salah satunya yaitu dengan memanfaatkan cache memory yang berfungsi sebagai perantara antara processor dan main memory.

Cache memory merupakan sebuah memory semikonductor yang merupakan tempat untuk menyimpan serangkaian data atau instruksi yang berasal dari memory lain yang relatif lebih lambat (Kumar \& Pradesh, 2016). Cache memory didesain untuk mengkombinasikan memory access time dari memory mahal yang berkecepatan tinggi dengan memory berukuran besar, berkecepatan lebih rendah dan berharga lebih murah. Dimana terdapat memory yang relatif lambat dan berukuran besar bersamaan dengan cache memory yang lebih cepat dan lebih kecil. Cache berisi salinan sebagian dari isi main memory. Ketika processor berusaha untuk membaca sebuah word dari memory, pengecekan dilakukan untuk memeriksa apakah word yang dibutuhkan berada dalam cache. Jika ya, maka word tersebut dikirim ke processor. Jika tidak, sebuah block main memory yang terdiri atas beberapa word yang berukuran tetap, dikirim ke cache dan kemudian word tersebut dikirim ke processor. Karena fenomena locality of reference, maka ada kemungkinan bahwa referensi selanjutya ke lokasi memory yang sama atau word lain pada block tersebut.

\section{II.2 Elemen Perancangan Cache memory}

Terdapat beberapa penelitian terdahulu yang meneliti tentang pengaruh penerapan berbagai elemen perancangan terhadap kinerja dari sebuah cache memory. Dimana yang dimaksud dengan kinerja cache memory dalam hal ini memiliki beberapa parameter, diantaranya seperti yang disebutkan pada (Kumar \& Pradesh, 2016) bahwa basis utama perhitungan kinerja
Tati Erlina, Rahmi Eka Putri

Jurnal Ilmiah Teknologi Informasi Terapan

Volume IV, No 1, 15 Desember 2017 
cache memory adalah miss rate, miss penalty dan average access time. Miss rate adalah akses terhadap bagian main memory yang salinannya tidak dapat ditemukan pada cache memory, sebaliknya hit rate adalah akses terhadap bagian dari main memory yang salinannya dapat ditemukan di cache memory. Miss penalty adalah jumlah total CPU cycles yang terhenti akibat usaha untuk mengakses main memory.

Walaupun terdapat sejumlah implementasi cache, terdapat beberapa elemen perancangan dasar yang berfungsi untuk mengklasifikasikan dan membedakan arsitektur cache (Stallings, 2013). Elemen-elemen perancangan cache tersebut dijelaskan sebagai berikut:

\section{Alamat Cache (Cache Address)}

Hampir semua nonembedded processor, dan banyak embedded processor, mendukung virtual memory. Pada dasarnya, virtual memory adalah sebuah fasilitas yang mengizinkan program untuk mengalamati memory dari sudut pandang logika, tanpa tergantung pada jumlah main memory yang tersedia secara fisik. Ketika virtual memory digunakan, field alamat dari instruksi mesin berisi alamat virtual. Untuk membaca dan menulis dari memory, sebuah hardware memory management unit (MMU) menterjemahkan setiap alamat virtual menjadi alamat fisik dalam main memory.

\section{Ukuran Cache (Cache Size)}

Perancang cache menginginkan cache dengan ukuran yang cukup kecil sehingga dengan demikian harga rata-rata harga per bit mendekati harga main memory dan cukup besar sehingga waktu akses ratarata secara keseluruhan mendekati cache itu sendiri. Terdapat beberapa motivasi untuk meminimalisasi ukuran cache. Dimana semakin besar cache, semakin besar jumlah gate yang terlibat dalam pengalamatan cache. Akibatnya, cache yang besar cendrung agak lebih lambat dibanding dengan cache yang lebih kecil -bahkan ketika dibangun dengan teknologi IC (Integrated) yang sama dan diletakkan pada tempat yang sama dalam chip dan papan sirkuit. Ketersediaan chip dan area papan sirkuit juga membatasi ukuran cache. Karena kinerja cache sangat sensitif terhadap sifat alami dari beban kerjanya, maka tidaklah mungkin untuk mendapatkan ukuran cache yang optimum.
Teknik Pemetaan (Mapping Techniques)

Mapping techniques digunakan untuk memetakan main memory blocks yang jumlahnya sangat besar ke cache memory lines yang jumlahnya jauh lebih kecil serta untuk membuat tanda (tag) berupa bits pada setiap memory cache line untuk memastikan main memory blocks yang mana yang salinannya sedang tersedia pada cache memory line tertentu. Terdapat beberapa mapping techniques yang berperan menentukan organisasi dari sebuah cache, yaitu direct mapping, associative mapping dan set associative mapping.

Direct mapping merupakan teknik yang paling sederhana, memetakan setiap block main memory ke hanya satu cache line yang mungkin.

Associative mapping menangani kelemahan dari direct mapping dengan mengizinkan setiap block main memory dimuat ke setiap line yang ada pada cache. Dalam hal ini, cache control logic menginterpretasikan sebuah memory address hanya sebagai sebuah Tag and sebuah Word field. Tag field secara unik mengidentifikasikan sebuah block main memory. Untuk mengetahui apakah sebuah block ada dalam cache, cache control logic harus secara simultan memeriksa setiap tag line untuk mengetahui yang sesuai.

Set associative mapping (disebut juga dengan $k$ way set associative) merupakan sebuah kompromi yang memperlihatkan kelebihan dari pendekatan direct dan associative dan sekaligus memperkecil kekurangannya. Dalam hal ini, cache terdiri atas serangkaian set, dimana masing-masingnya terdiri atas sejumlah lines.

\section{Algoritma Penimpaan (Replacement Algorithm)}

Replacement algorithm memiliki peranan penting dalam perancangan cache memory karena replacement algorithm berperan untuk memutuskan cache memory line mana yang akan ditimpa oleh main memory block yang dibutuhkan. Terdapat 3 (tiga) alternantif replacement algorithm utama (Patterson \& Hennessy, 2009), yaitu First In First Out (FIFO), Least Frequently Used (LFU), Least Recently Used (LRU) dan Random. 


\section{Aturan Penulisan (Writing Policy)}

Writing policies berperan untuk menentukan bagaimana cara menjaga konsistensi antara isi cache memory line tertentu dengan main memory block terkait. Alternatif metode yang tersedia diantaranya adalah write back dan write through. Pada write back operasi penulisan hanya dilakukan pada cache memory line, sedangkan isi main memory block diperbaharui hanya ketika cache memory line yang terkait dengannya akan dihapus dari cache memory. Sedangkan pada write through, operasi penulisan dilaksanakan pada main memory block bersamaan dengan penulisan pada cache memory lines.

\section{II.3 Software Simulator Cache memory}

Pemilihan nilai atau teknik yang berbeda pada parameter-parameter perancangan cache memory sebagaimana dijelaskan diatas, dapat mempengaruhi kinerja dan konsumsi daya pada cache memory (Upadhyay 2016). Oleh karena itu untuk memilih konfigurasi terbaik dari sebuah cache maka diperlukan eksplorasi elemen-elemen perancangan cache. Penelitian (D. M. Cambre, E. Boemo, and E. Todorovich, 2008) mempelajari tentang hubungan antara instruksi dan ukuran data cache memory dan kemudian menganalisa hubungannya dengan konsumsi daya. Diketahui bahwa menggunakan cache size yang optimal dapat menghasilkan konsumsi daya terendah walaupun tetap mempertimbangkan waktu eksekusi, daya dan pemanfaatan sumberdaya-sumberdaya yang terdapat dalam sebuah FPGA.

Sebuah simulator untuk Memory Systems pada Symmetric Multiprocessors (SMPCache), yaitu sebuah alat bantu dari Department of Computer and Communication Technologies at the University Extremadura Escuela Politecnica di Spanyol. SMPCache (M. Á. Vega Rodríguez, J. M. Sánchez Pérez, and J. A. Gómez Pulido, 2001) adalah sebuah trace driven simulator yang digunakan untuk menganalisa dan mensimulasikan cache memory systems pada symmetric multiprocessors yang menggunakan bus yang berbasis shared memory. Simulator ini memungkinkan user untuk mengkonfigurasi arsitektur berbagai macam processor dengan merubah beragam parameter seperti: jumlah processors, cache coherence protocol, skema arbitrasi, panjang word (word length), jumlah word dalam sebuah block, ukuran memori (memory size), jumlah tingkatan cache memory, teknik pemetaan cache memory (mapping techniques), ukuran block cache memory (line size), aturan penimpaan dan penulisan pada cache memory (replacement policies). Setelah memilih arsitektur tertentu pada cache memory tersebut, maka arsitektur tersebut diuji menggunakan benchmarks yang disediakan oleh simulator tersebut. Dimana, secara umum terdapat dua kategori benchmarks yaitu: sembilan buah benchmark untuk arsitektur processor tunggal dan empat buah benchmark untuk arsitektur multicore computer. Setelah pengujian dilakukan, simulator tersebut menyajikan sejumlah karakteristik dari cache memory seperti jumlah arbitrasi bus, jumlah block yang diangkut melalui bus tersebut, jumlah memory akses (pengambilan, pembacaan dan penulisan data), jumlah cache hit dan cache miss dalam cache memory.

CACTI (S. Thoziyoor, J. H. Ahn, M. Monchiero, J. B. Brockman, and N. P. Jouppi, 2008) adalah sebuah software simulasi yang digunakan untuk menganalisa daya, area dan timing untuk arsitektur yang berbasis memori. CACTI (HP Labs, 2008) merupakan sebuah model terintegrasi untuk mensimulasikan cache memory dan main memory access time, cycle time, area, leakage dan dynamic power. Simulator ini ditujukan untuk digunakan oleh computer architects untuk memahami kompromi kinerja dalam organisasi sistem memori.

\section{Pemodelan dan Analisa Hasil SIMULASI}

Secara umum, analisis dan perancangan dalam penelitian ini dilakukan melalui langkah-langkah yang terdapat pada gambar 1 .

Dalam penelitian ini, terdapat 2 jenis peubah yang diamati, yaitu pertama, peubah yang akan diamati dalam penelitian ini adalah besarnya cache hit sebagai salah satu peubah yang dijadikan parameter kinerja dari sebuah cache memory yang dihasilkan dari berbagai macam kombinasi input yang diberikan dan berbagai macam teknik dari elemen perancangan yang diterapkan.

Kedua, peubah yang diamati adalah daya yang dikonsumsi sebuah cache memory. Hal ini juga dipengaruhi oleh elemen perancangan cache memory. Dimana penerapan sebuah teknik yang berbeda dapat memberikan pengaruh terhadap besarnya konsumsi daya dari suatu cache memory.
Tati Erlina, Rahmi Eka Putri

Jurnal Ilmiah Teknologi Informasi Terapan

Volume IV, No 1, 15 Desember 2017 


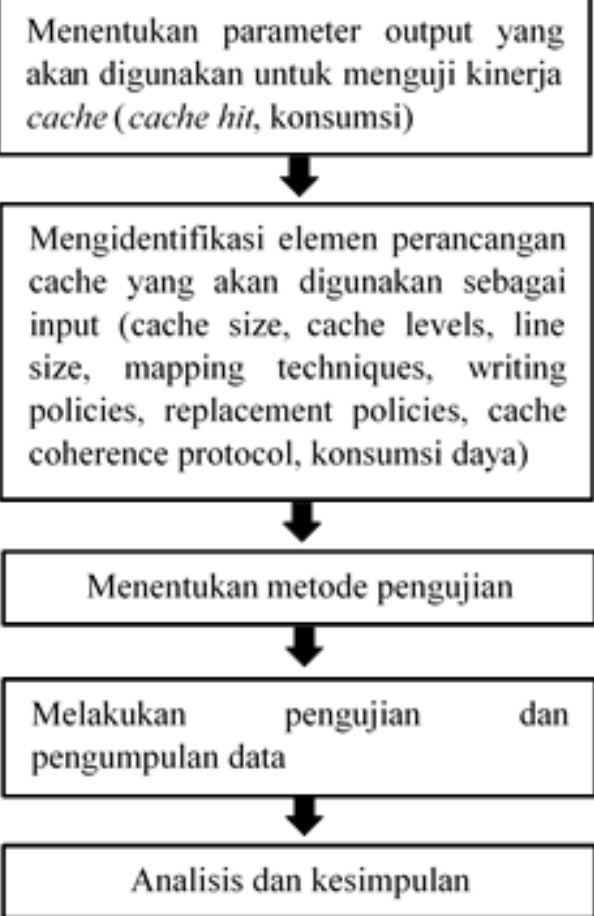

Gambar 1. Metodologi Penelitian

Langkah pengumpulan data dilakukan sebagai berikut: Pertama, mengkonfigurasi SMPCache dengan menggunakan elemen perancangan seperti jumlah processor, cache coherence protocol, bus arbitration, word wide, blocks in main memory, line size, block in cache, mapping, writing strategy dan replacement policy tertentu, menjalankan SMPCache dengan konfigurasi tersebut dan merekam tingkat miss rate yang dihasilkan sebagai salah satu parameter kinerja cache memory (langkah ini diulangi dengan menggunakan setiap kemungkinan kombinasi konfigurasi yang ada). Kedua, mengkonfigurasi CACTI cache simulator dengan menggunakan konfigurasi yang sama dengan yang digunakan pada SMPCache dan menjalankan setiap kombinasi aspek perancangan yang digunakan untuk mengetahui besarnya konsumsi daya dari setiap konfigurasi yang digunakan. Ketiga, menganalisa hubungan antara keluaran SPMCache dan CACTI cache simulator yang menggunakan konfigurasi yang sama, kemudian membandingkan keluaran tersebut dengan keluaran kedua simulator tersebut saat menggunakan kombinasi konfigurasi lainnya, kemudian menganalisa data secara keseluruhan.

Menjalankan SMPCache dengan
konfigurasi elemen perancangan cache
yang sudah ditetapkan (jumlah processor,
cache coherent protocol, bus arbitration,
word wide, blocks in main memory, line
size, block cache, mapping techniques,
writing strategy dan replacement policy)

Gambar 2. Langkah Pengujian dan Pengumpulan Data

\section{III.1 Hasil Simulasi Menggunakan SMPCache}

Pengujian dengan menggunakan software simulasi ini adalah untuk mengetahui pengaruh perubahan pada fungsi pemetaan yang digunakan terhadap cache hit (melalui penghitungan persentase cache miss) yang dihasilkan.

Pengujian dilakukan pada processor tunggal dan multicore, dengan menggunakan Cache coherence protocol = MESI, Scheme for bus arbitration = Random, Word wide (bits) $=32$, Words by block $=64$ (block size $=256$ bytes), blocks in main memory $=4096$ ( main memory size $=1024 \mathrm{~KB}$ ) dan replacement policy $=$ LRU.

Tati Erlina, Rahmi Eka Putri 


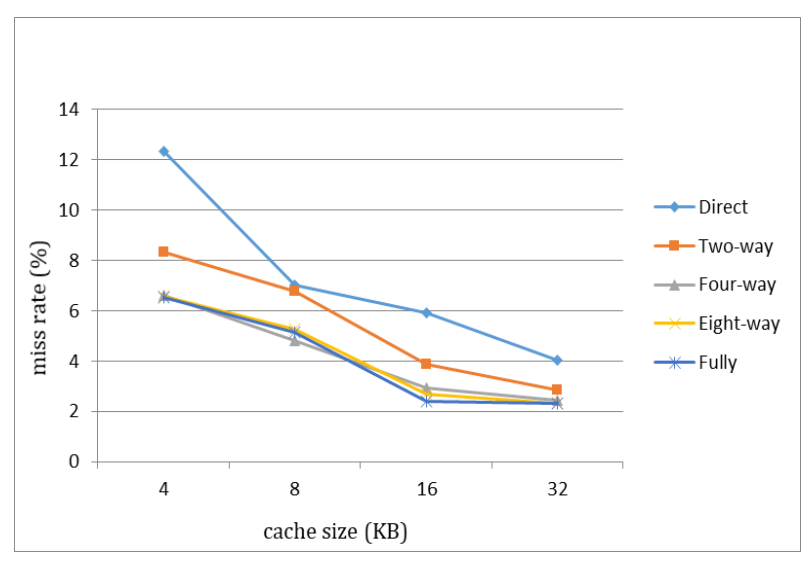

Gambar 3. Pengaruh Tingkat Associativity dan Cache Size terhadap miss rate

Dari grafik diatas dapat diketahui bahwa persentase miss rate menurun seiring dengan meningkatnya tingkat associativity. Dimana yang dimaksud dengan tingkat associativity di sini adalah jumlah line yang terdapat pada sebuah rangkaian (set) yang pada akhirnya menentukan jumlah set keseluruhan yang terdapat pada sebuah cache memory.

$$
\begin{gathered}
m=\mathrm{v} \times \mathrm{k} \\
i=j \operatorname{modulp} v
\end{gathered}
$$

dimana,

$$
\begin{array}{ll}
i & =\text { cache set number } \\
j & =\text { main memory block number } \\
m & =\text { number of lines in the cache } \\
v & =\text { numbers of sets } \\
k & =\text { number of lines in each set }
\end{array}
$$

Tingkat associativity juga memiliki pengaruh terhadap persentase miss rate ketika ukuran cache diperbesar. Dalam hal ini, semakin besar ukuran cache, maka jumlah line yang tersedia pada cache tersebut untuk menampung block yang disalin dari main memory semakin banyak, sehingga ketika processor meminta data yang tersimpan di alamat memory tertentu, kemungkinan besar block tersebut ada di dalam cache (cache hit). Akan tetapi, pengaruh cache size tersebut semakin kecil untuk menurunkan tingkat miss rate seiring dengan meningkatnya ukuran cache. Dimana ketika cache size diperbesar dari 16KB menjadi $32 \mathrm{~KB}$, persentase cache miss-nya cendrung tidak berubah.

\section{III.2 Hasil Simulasi Menggunakan CACTI}

Pengujian dengan menggunakan simulator CACTI dilakukan untuk mengetahui pengaruh tingkat associativity yang diterapkan terhadap dynamic power, leakage power serta total power yang dikonsumsi. Pengujian dilakukan pada teknologi IC (Integrated Circuit) $32 \mathrm{~nm}, 45 \mathrm{~nm}, 65 \mathrm{~nm}$ dan $90 \mathrm{~nm}$ dengan 64KB caches dengan 64-byte cache lines.

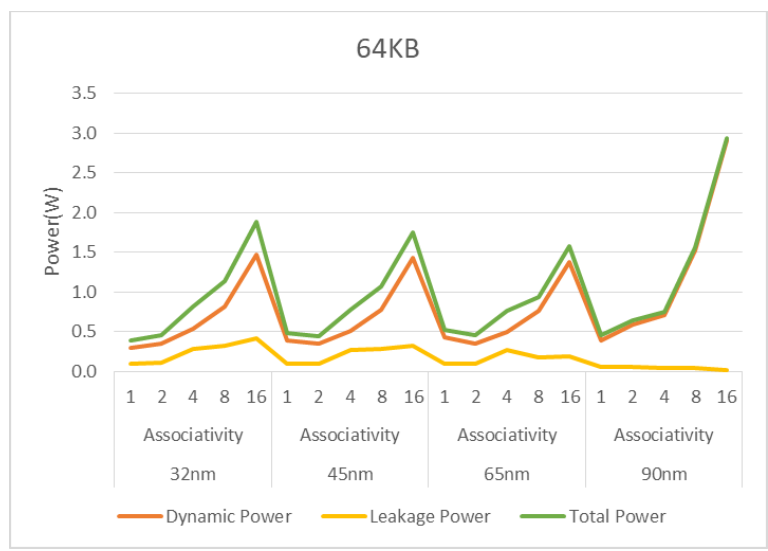

Gambar 4. Pengaruh Assosiatifitas terhadap Konsumsi Daya

Dari pengujian tersebut diketahui bahwa tingkat associativity berpengaruh terhadap besarnya leakage power (static power) yaitu konsumsi daya yang terjadi saat tidak ada aktifitas dalam rangkaian, dan dynamic power (konsumsi daya saat input bernilai aktif) pada sebuah cache. Dimana Semakin tinggi tingkat associativity pada sebuah cache yang berukuran sama, semakin besar pula jumlah konsumsi daya cache tersebut.

Untuk ukuran cache yang berbeda, pola yang hampir sama juga terjadi. Secara umum jumlah konsumsi daya tersebut cendrung sedikit menurun seiring dengan meningkatnya technology processor yang digunakan. Akan tetapi, perubahan yang sangat signifikan terjadi pada technology IC 90nm dimana konsumsi daya totalnya meningkat secara tajam seiring dengan peningkatan jumlah associativity terutama dari 8-way ke 16 way associativity.

\section{KESIMPULAN DAN SARAN}

Dari eksperimen-eksperimen yang dilakukan diketahui bahwa jenis pemetaan sangat berpengaruh terhap persentase miss rate yang terjadi pada sebuah cache. Dimana semakin tinggi tingkat associativity,

Tati Erlina, Rahmi Eka Putri 
semakin rendah miss rate yang terjadi pada sebuah cache. Artinya adalah kinerja cache tersebut meningkat dari segi cache hit yang terjadi. Akan tetapi, peningkatan kinerja tersebut juga harus diiringi oleh peningkatan konsumsi daya. Penelitian tentang pengaruh aspek-aspek lain dari perancangan cache memory perlu ditelaah lebih lanjut sehingga didapatkan trade off yang optimal antara kinerja yang diperoleh dari peningkatan associativity dengan peningkatan jumlah daya yang diperlukan.

\section{REFERENSI}

K. Saito, R. Kobayashi, and H. Shimada, "Reduction of Cache Energy by Switching between Ll High Speed and Low Speed Cache under application of DVFS," in International Conference On Advanced Informatics: Concepts, Theory And Application (ICAICTA), 2016.

D. P. Kothari, "A Study on Factors Influencing Power Consumption in Multithreaded and Multicore CPUs," WSEAS Trans. Comput., vol. 10, no. 3, pp. 93-103, 2011.

Z. Zhu, "Power Efficient Designs." [Online]. Available:

http://home.eng.iastate.edu/ zzhang/courses/ cpre585-f04/slides/Lecture24.pdf. [Accessed: 22-Feb-2017].

J. Abella and A. Gonzalez, "Power efficient data cache designs," in Proceedings 21st International Conference on Computer Design, 2003, no. 3, pp. 8-13.

S. Kumar and U. Pradesh, "An Overview of Modern Cache and Performance Analysis of Replacement Policies," in IEEE International Conference on Engineering and TEchnology (ICETECH), 2016, no. March, pp. 210-214.

W. Stallings, Computer Organization and Architecture: Designing for Performance, Ninth Edit. Pearson, 2013.

D. A. Patterson and J. L. Hennessy, Computer Organization and Design: The Hardware/Software Interface, vol. 4th, no. 0. 2009.
B. R. Upadhyay and S. TSB, "Design Space Exploration of Cache memory - A Survey," in International Conference on Electrical, Electronics, and Optimization Techniques (ICEEOT), 2016, pp. 2294-2297.

D. M. Cambre, E. Boemo, and E. Todorovich, "Energy Evaluation in the Nios II Processor as a Function of Cache Sizes," in Southern Conference on Programmable Logic, 2008, pp. 55-61.

M. Á. Vega Rodríguez, J. M. Sánchez Pérez, and J. A. Gómez Pulido, "An educational tool for testing caches on symmetric multiprocessors," Microprocessors and Microsystems, 2001.

S. Thoziyoor, J. H. Ahn, M. Monchiero, J. B. Brockman, and N. P. Jouppi, "A comprehensive memory modeling tool and its application to the design and analysis of future memory hierarchies," Proc. - Int. Symp. Comput. Archit., pp. 51-62, 2008.

[11] HP Labs, "CACTI - An integrated cache and memory access time, cycle time, area, leakage, and dynamic power model," 2008. [Online]. Available: http://www.hpl.hp.com/research/cacti/. [Accessed: 23-Feb-2017]. 